\title{
HIV and AIDS related knowledge, beliefs and attitudes among rural communities hard to reach in Sudan
}

\author{
Amar Hassan Khamis* \\ ${ }^{1}$ Department of Family and Community Medicine, University of Dammam, Dammam, KSA; \\ *Corresponding Author: ammmarhasssan@hotmail.com
}

Received 3 April 2013; revised 4 May 2013; accepted 17 June 2013

Copyright (C) 2013 Amar Hassan Khamis. This is an open access article distributed under the Creative Commons Attribution License, which permits unrestricted use, distribution, and reproduction in any medium, provided the original work is properly cited.

\begin{abstract}
Background and Objective: There is a rising concern about Human Immunodeficiency Virus/Acquired Immunodeficiency Syndrome (HIVIAIDS) related knowledge in rural communities of Sudan. This study focuses on determining the extend of knowledge, beliefs, and attitudes about HIVI AIDS among rural communities difficult to access in the six States of Sudan. Subjects and Methods: Six thousand and one hundred twenty five respondents were interviewed through the method of house-to-house visits. A structured questionnaire was administered by research assistants recruited from the Faculty of Medicine, Khartoum University during a rural residency campaign in six states of Central, Eastern and Northern Sudan during 2008/2009. Results: Of the total interviewees, $48 \%$ were aware of the HIVIAIDS risk; $46 \%$ reported to have good health seeking behaviors for HIVIAIDS. $54.4 \%$ of women reported to have better knowledge about the disease than men (45.6\%). 38\% (2005) had not heard of safety use of condom whereas $16 \%$ (320) had used it. Logistic regression revealed that $5.3 \%$ of knowledge about the disease was explained by gender, education and religion adjusted over age of the respondents. Conclusions: Mass media were the most common source of information about the existent risk of HIVIAIDS in rural communities. These findings could assist Sudanese National Aids Programme (SNAP), healthcare providers and policymakers to develop informative materials and health education programs to educate rural community is about the risk of HIVIAIDS.
\end{abstract}

Keywords: HIVIAIDS; Knowledge; Beliefs;
Attitudes; Sudan

\section{INTRODUCTION}

Sudan is the second largest country in Africa bordered by ten countries, some of which have high prevalence of Human Immunodeficiency Virus (HIV) and Acquired Immunodeficiency Syndrome (AIDS) [1]. In 2005, after signing a peace treaty between north and south to end over twenty years of civil war, many refugees in these neighboring countries returned home. This raised a concern among the community that some of these returnees may have been infected with HIV and were unaware of it, which would significantly add to the current estimates of 600,000 living with HIV/AIDS in the country [2]. The disease is more frequent in the age groups of $15-45$, and $40 \%$ of the population is in this age range [3]. In 2007 alone, the confirmed cases of the virus reached 290,000. Of these, 4060 (1.4\%) infected were adults aged 15 - 49 years old, with women constituting $59 \%$ of this age group. The estimated number of infected children less than 15 years was 25,000, and the number of deaths exceeded 25,000 . These figures place Sudan at an intermediate HIV and AIDS prevalence of 1.6\% [3-6].

There is an increasing concern among public concerning the threat posed by the AIDS epidemic, especially in rural communities. Approximately $70 \%$ of Sudanese people living in the countryside have insufficient information or knowledge about the risks of HIV/AIDS [7]. The inadequate knowledge about AIDS may be related to numerous factors including AIDS related-stigma, fear of contagion and false beliefs and attitudes towards people infected with the virus.

AIDS-related stigma seems to serve as a barrier to delivering effective information and knowledge to these remote communities. It represents prejudice and discrimination directed at people perceived to have AIDS or HIV, 
as well as the individuals, groups, and communities with whom they are associated [8-11]. According to this definition, infected persons are considered to have fallen short of normative social and religious expectations of a conservative society such as that of rural communities [8]. The primary sources of stigma are negative religious and social attitudes about the disease and the people infected with it. In the religious view, HIV/AIDS is largely correlated with homosexuality and sexual relations outside marriage [12]. In Islam, as in other religions, these practices are condemned and regarded as immoral behaviour that predisposes people to physical and social diseases, and therefore, are forbidden and punished by God. In other words, the sinful individuals have gotten what they deserve, or as one Western policymaker described it more bluntly as nature's form of retribution against homosexuals [13]. Thus, the conservative rural people have become more sensitive to AIDS-related knowledge, preventive measures employed to fight against the disease and groups associated with it, such as those who advocate the use of condoms, Men who have sex with Men (MSMs) and others [12]. To them, the disease is highly contagious, embarrassing, intolerable to the public and health providers, and eventually leads to death [14]. Their hostility is not only directed towards the infected persons but also towards anti-AIDS campaigners who continually try to spread knowledge about the disease [15]. In their coercive/compassion dimension, Herek and Glunt (1991) viewed people's negative attitudes towards AIDS as highly contagious and include attributions of blame to those who have become infected. Fear of contagion was reported among $79 \%$ of Sudanese dental students investigated about providing health services to HIV/AIDS patient [1].

Despite beliefs to the contrary [16], rural people still hold misconceptions that HIV/AIDS can be transmitted by nonsexual modes such as handshakes, sharing food, or being in a room with the infected person [17]. In addition, they view themselves as not among the most-at-risk groups since disease is believed to be highly prevalent among certain vulnerable groups such as refugees, internally displaced people, truck drivers, tea-sellers, sex workers and men who have sex with men [18]. In Sudan, tea sellers are a group of women sitting on the streets in the capital and other major cities and illegally selling tea and food items to their customers [15]. A national survey conducted in 2002 reported the HIV prevalence among these women to be highest at 2.5\% [19]. All these factors combined negatively influence the attitudes of rural people not only in obtaining adequate knowledge about the disease but also in undermining the use of protective measures used to address it.

Despite the fear-mongering, efforts to curb the disease through public education by government and other agencies are increasing. For instance, in 2003, the Sudanese
People Living with HIV/AIDS Care Association (SPLWHACA) was established in Khartoum to provide counselling and support to all persons infected with HIV /AIDS. The work of the association has expanded to teach the community about the means of contracting and of preventing the disease as well as fighting stigma, shame and deeply-held prejudice experienced by the infected people. At the governmental level, new curricula on disease protection have been developed by the Ministry of Education to educate 2.5 million elementary and high school students aged 10 - 18 years old about the risks of unprotected sex (29) The government efforts were expanded to instruct the public about the safety measures through the use of condoms in order to respond to the call of the United Nations Millennium Development Declaration (UNMDD) signed in 2000 to provide fund projects dedicated to eradicating the spread of HIV/AIDS [20]. The non-governmental organizations (NGOS) have also played a significant role in combating HIV/AIDS in Sudan. They have carried out a pilot prevention project of the International Rescue Committee (IRC) aimed at increasing the awareness of HIV/AIDS and improving reproductive health practices and health facilities in south Sudan [15].

Mass media (e.g., radio, television, magazine, newspapers) are known to play a pivotal role in fighting against HIV/AIDS. It functions as an agency of significant influence that provides wide-reaching communication to heterogeneous audiences simultaneously with uniform messages [14]. The main goals of media are to raise awareness of the existence of HIV/AIDS, modes of transmission and means of prevention [17]. In Sudan, over 90\% of population knows the basic facts about HIV/AIDS [5], but the use of media in combating the disease has not been fully utilized. This may be related to several reasons including the vast geographical area of Sudan, different ethnic and cultural groups, limited resources and access to media channels and the lack of interest in acquiring knowledge about a disease equated with a promiscuous lifestyle.

Nevertheless, mass media continue to play a role in addressing psychosocial factors negatively affecting knowledge and attitudes among the rural people. For instance, a national survey conducted among Sudanese dental students reported $44.1 \%$ of participants identified radio and television as their primary source of information about HIV/AIDS, more than healthcare providers (39.3\%) and significant others (31.3\%) [5]. Similar results were reported in the United States where $72 \%$ of participants identified television, radio and newspapers as their primary HIV/AIDS-related information more than doctors, friends and family [4].

The purpose of the present study is to assess the HIV /AIDS related-knowledge, beliefs and attitudes among 
rural communities in Sudan.

\section{METHOD AND MATERIALS}

The study was designed as a cross-sectional survey. Data was collected from permanent residents of rural communities to investigate their knowledge, attitudes and beliefs about HIV/AIDS and provide them with health education concerning the risks of the disease.

\subsection{Sample Selection}

Administratively, Sudan is divided into 26 states. Six were selected for the study, including Northern, River Nile, Gezira, Gadarif, White Nile and Sinnar states. At least five rural hospitals in each of these six states were identified for the study on the basis of following criteria: 1) presence of rural population utilizing primary healthcare services, and 2) availability and accessibility of medical officers to welcome and house 15 research assistants (RAs) for a period of 15 days. The hospitals were used as centers to identify the populations utilizing their services. In the target areas, house-to-house; based on systematic sampling over street where these houses were located; visits among permanent residents were carried out by RAs. Both males and females who fulfilled the study's inclusion criteria were interviewed.

\subsection{Ethical Consideration}

All participants were informed of the objectives and confidential nature of the survey and that there would be no negative consequences for declining to participate even if they agreed initially. Hence, they freely consented to participate in the interview. Ethical approval of the work was obtained from the Dean of Faculty of Medicine and authorities of each rural state hospital used as a center for target population.

\subsection{Questionnaire}

A structured questionnaire, designed by Sudan National Aids Program (SNAP) was administered to all participants involved in the study. It was based on a literature review similar to other surveys replicated locally and internationally [21]. A panel from the Department of Community Medicine reviewed and validated the questionnaire. Minor modifications were made in one or two items. The questionnaire items included the following variables: knowledge about HIV/AIDS, modes of transmission, prevention, availability of voluntary testing, knowledge on availability of health services and source of information about HIV/AIDS. The items were written in simple Arabic that resembled common speech so that the participants with limited education would be able to read and understand them comfortably.

\subsection{Data Collection Procedure}

RAs were recruited from 5th year-medical students at Khartoum University. They were all native Sudanese in their early $20 \mathrm{~s}$ who joined rural residency campaigns in the six states during summers of 2008/2009. At the preliminary stage of the survey, RAs were trained in the use of the survey questionnaire using students who did not participate in the study. They commenced house-tohouse visits by contacting households and interviewing them. Follow up visits were conducted to ensure the accuracy of responding to all items and that Participants were able to complete the questionnaires independently and without interference nor assistance from relatives.

\subsection{Data Analysis}

Statistical Package of Social Science (SPSS Inc.; Chicago, Illinois) version 16 was used for data management and analysis. Descriptive statistics including frequencies, means, median, and standard deviation were performed to give general descriptions of the data. Chi-square test was performed to examine differences in knowledge. Logistic regression was used to study the demographical data, and association between knowledge, health seeking behavior and stigma. The level of statistical significance was set at $5 \%$.

\section{RESULTS}

\subsection{Characteristics of Respondents}

Of the 6125 respondents; none of the household or individual declined to participate in the survey, some selected houses found empty during first visit was covered during successive ones; the range of the age of respondents was 15 - 90 years; the mean age was (30.44 \pm 10.23$)$ years; and 3607 (58.9\%) were females. A majority of the respondents [(1944) 69.8\%] reported that they were currently working, 624 (10.9\%) were still attending school, 1050 (17.1\%) were housewives and 154 (2.6\%) were jobless. Among 6054 of respondents who answered the question about the level of education, $35.5 \%$ of the respondents reported secondary school as their highest education level, 30.9\% of respondents completed their primary school of education, $15.4 \%$ of the respondents were university graduated and $15.4 \%$ of the respondents were illiterate. Most (63.6\%) of the respondents were married, divorced or widowed. The survey revealed that 5915 (97.0\%) were Muslims, 165 (2.7\%) were Christians, and $15(0.2 \%)$ of other religions.

\subsection{Descriptive Outcomes Knowledge about HIVIAIDS}

Figure 1 shows that $5.1 \%$ of respondents $(n=310)$ had never heard about HIV/AIDS; with a wide variation among the states. Of those that had heard of HIV/AIDS (n 


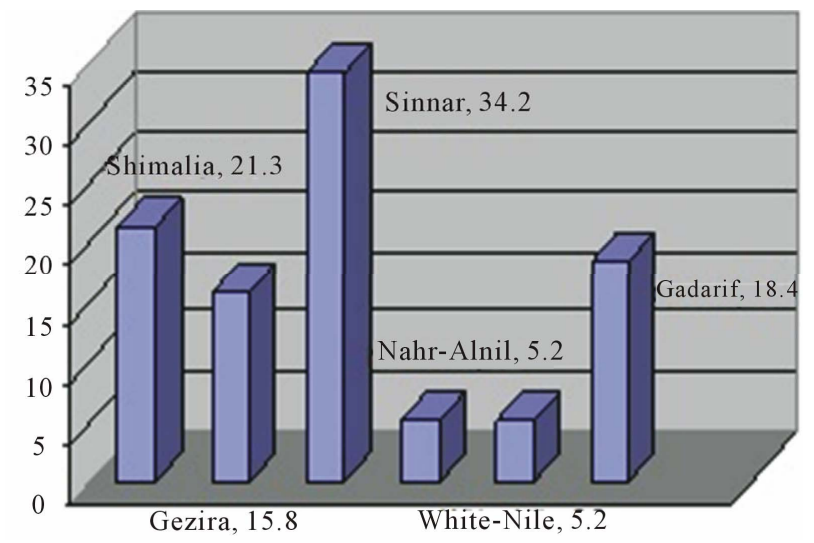

Figure 1. Distribution of ignorance of HIV by State (\%).

= 2679), when further asked about ways of protection from HIV and AIDS, $(84.1 \%, \mathrm{n}=2262)$ had no idea about ways of protection from HIV/AIDS.

\subsection{Sources of Information}

Figure 2 shows that the main source of information about HIV/AIDS was the mass media, with Radio and TV ranking first, 3895 (66.2\%) and 3802 (64.6\%) respectively, followed by newspapers 1995 (33.9\%). Other source of information include relatives 1595 (27.1\%), health worker 1342 (22.8\%), and others 645 (11\%).

\subsection{Knowledge about HIV}

Table 1 shows the specific knowledge about the HIV/ AIDS. Misconceptions were noted relating to HIV/AIDS modes of transmission. Three hundred and four $(4.9 \%)$ individuals had not heard about HIV/AIDS; in these rural areas. The percentage of those who gave correct answers of sexual intercourse with someone infected with AIDS is possible transmission route is $81.4 \%$, while $1083(18.6 \%)$ have not heard about this vital and main mode of transmission in Sudan. Three thousand and seven hundred forty one 3741 (63.3\%) of participants were aware that infected blood can transmit the HIV virus. Sharing injection needles with someone with AIDS is possible transmission route was known by 4152 (70.6\%) of the participants. "Mother to child transmission" was considered a possible route of transmission by 2133 (36\%) respondents. About 2806 (48.8\%) considered "Shaking hands" a possible transmission route. A total of 2640 (47.8\%) of the respondents considered that "Mosquito bites are a possible cause of infection. A considerable proportion of the respondents [2919 (50.8\%)] said that "eating or drinking with a person with AIDS is a possible transmission route" while 1949 (48.9\%) acknowledged "living in the same location with someone with AIDS" is a possible transmission route.

Almost all respondents acknowledged the possibility of prevention of HIV/AIDS (95\%). Respondents were rela-

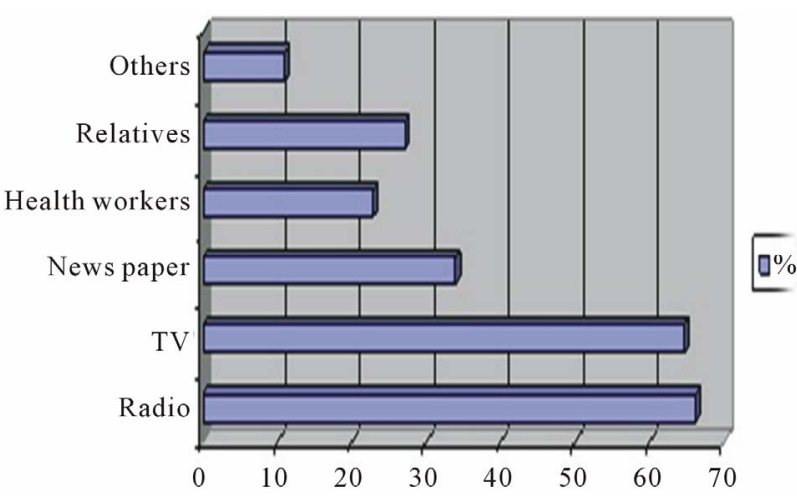

Figure 2. Sources of information about HIV/AIDS from 6125 respondents.

tively well informed about prevention compared to the knowledge of modes of transmission of HIV/AIDS.

Out of 5249 who responded to the questions about condoms, only 2005 (38.2\%) had heard about condoms. Among this group only 320 (16\%) had used them. The reported use of condoms among men was $46.8 \%$ by both sexes was $33.9 \%$, and rarely in $19.4 \%$. [The proposition came from women Adherence is higher among males (56.6\%) compared to females (43.5\%). I do not understand this part]. Only $47.6 \%$ of the respondents were aware that the use of condoms could prevent HIV. Among all participants in the study, 4656 (78.8\%) of them acknowledged that "forbidding sex outside marriage is a method of prevention".

\subsection{Health Seeking Behavior}

Table 2 shows types of health seeking behavior with respect to HIV/AIDS, few respondents had had a test for HIV, 561 (9.6\%) of them have been tested. About 2630 (44.9\%) of the respondents have been exposed to educational materials about HIV/AIDS in the past. The perceptions of respondents on the best way of obtaining knowledge about HIV/AIDS were: TV, symposia, public lectures, radio, mosques, churches, school awareness and curricula, pamphlets and newspapers.

Stigma about individuals affected by HIV/AIDS in terms of isolation of affected individual was reported by 2267 (37\%) of the respondents, that affected individuals should be treated as normal people with all their rights respected was reported by 2741 (47.2\%) of the respondents while $737(12.7 \%)$ of the respondents considered them as bad, immoral individuals who should be punished. Voluntary testing was not popular among respondents and only 618 (10.7\%) of the respondents were tested.

Table 3 shows that the majority of the respondents 926 (41.2\%) were not tested; because they were confident about the fact that they cannot be affected by HIV. The rest of the reasons that prevented respondents to test ranked as follows: no infection, ignorance about tests, 
Table 1. Shows respondents items of knowledge about HIV/AIDS.

\begin{tabular}{|c|c|c|c|}
\hline Items of knowledge & Correct & Correct & Answer \\
\hline & Response & No. & $\%$ \\
\hline Heard about HIV & Yes & 5776 & 94.9 \\
\hline Sexual intercourse with an AIDS person is possible transmission route & True & 4741 & 81.4 \\
\hline Infected blood can transmit the virus & True & 3741 & 63.3 \\
\hline Sharing the same skin injectors with AIDS is possible transmission route & True & 4152 & 70.6 \\
\hline Mother to child infection is a possible transmission route & True & 2133 & 36.0 \\
\hline Shaking hands with a person with AIDS is possible transmission route & False & 2944 & 51.2 \\
\hline Mosquito bites are one possible cause of infection & False & 2883 & 50.2 \\
\hline Eating or drinking with someone with AIDS is possible transmission route & False & 2827 & 49.2 \\
\hline Transmission if affected person shares the same space & False & 2037 & 51.1 \\
\hline HIV is not preventable & False & 296 & 5.1 \\
\hline HIV is preventable, but I do not know & True & 883 & 14.9 \\
\hline Heard about condom & True & 2005 & 38.2 \\
\hline Condom could prevent from HIV & True & 2785 & 47.6 \\
\hline Forbidding sex outside marriage is method of prevention & True & 4656 & 78.8 \\
\hline
\end{tabular}

Average of knowledge about HIV/Aids is $8.4(\mathrm{SD}=2.2)$.

Table 2. Shows individuals items of health seeking behavior towards HIV/AIDS.

\begin{tabular}{|c|c|c|}
\hline Items of knowledge & Correct & Answer \\
\hline & No. & $\%$ \\
\hline History of having had a test for HIV & 561 & 9.6 \\
\hline Best way to knowledge about HIV/AIDS is radio & 3068 & 51.8 \\
\hline Best way to knowledge about HIV/AIDS is TV & 3302 & 55.7 \\
\hline Best way to knowledge about HIV/AIDS is symposium and general lectures & 3220 & 54.3 \\
\hline Best way to knowledge about HIV/AIDS is cinema & 967 & 16.3 \\
\hline Best way to knowledge about HIV/AIDS is school curriculum & 2090 & 35.3 \\
\hline Best way to knowledge about HIV/AIDS is small books & 1311 & 22.1 \\
\hline Best way to knowledge about HIV/AIDS is pamphlets and news papers & 1571 & 26.5 \\
\hline
\end{tabular}

Average of health seeking behavior about HIV/Aids is 4.1 (SD = 2.7).

Table 3. Shows causes why individuals had not been tested themselves for HIV.

\begin{tabular}{ccc}
\hline Variables & & \\
\hline Self confidence & No. & $\%$ \\
No desire & 926 & 41.2 \\
Transmitted by diagnoses & 180 & 8.0 \\
Center not accessible & 45 & 2.0 \\
I am not infected & 126 & 5.6 \\
I have no chance & 377 & 16.8 \\
I do not know how to diagnose & 45 & 2.0 \\
Without any reason & 239 & 10.6 \\
I had not thought about this before & 218 & 9.7 \\
Financial reasons & 57 & 2.5 \\
I cannot accept the idea & 8 & 0.4 \\
I have not been exposed to the disease & 24 & 1.1 \\
\hline
\end{tabular}

without reason, no desire to know the diagnoses, and unavailability of center of diagnostic centers.

\subsection{Analytical Outcomes}

The distribution of score of knoweldge over the 16 items suggested. A cut off point of 8.5 has been used to split respondents as knowledgable or not. This new variable is used to test the association between different characteristics of respondents and knowledge.

Table 4 shows the association between knowledge about HIV/AIDS and demographic factors. Young age, female sex, higher level of education and currently married persons had better knowledge, as compared with others.

Logistic regression analysis with knowledge as an independent variable and demographic variables as explanatroy variables revealed that only $5.3 \%$ of knowledge 
Table 4. Association between knowledge and demographical factors.

\begin{tabular}{|c|c|c|c|}
\hline Characteristic & $\begin{array}{l}\text { Correct Knowledge No. (\%) [What are these \%? } \\
\text { They should add to } 100 \% \text { for each line, not each column.] }\end{array}$ & Incorrect Knowledge No. (\%) & p-value \\
\hline \multicolumn{4}{|l|}{ Age } \\
\hline$<20$ & 288 (13.6) & 397 (17.4) & \multirow{4}{*}{$<0.001$} \\
\hline $20-30$ & 882 (41.6) & $820(36.0)$ & \\
\hline $31-40$ & $482(22.8)$ & 521 (22.9) & \\
\hline$>40$ & $466(22.0)$ & $538(23.6)$ & \\
\hline \multicolumn{4}{|l|}{ Gender } \\
\hline Male & $1056(45.6)$ & $983(39.2))$ & \multirow{2}{*}{$<0.001$} \\
\hline Female & $1261(54.4))$ & $1526(60.8)$ & \\
\hline \multicolumn{4}{|l|}{ Religions } \\
\hline Muslim & 2279 (98.5) & 2412 (96.6) & \multirow{2}{*}{$<0.001$} \\
\hline Other & $34(1.5)$ & $81(3.2)$ & \\
\hline \multicolumn{4}{|l|}{ Education level } \\
\hline Illiterate & 178 (7.7) & $471(19)$ & \multirow{5}{*}{$<0.001$} \\
\hline Primary & 580 (25.1) & 864 (34.9) & \\
\hline Secondary & 962 (41.7) & 809 (32.6) & \\
\hline University & $528(22.9)$ & $528(22.9)$ & \\
\hline Post university & $14(0.6)$ & $9(0.4)$ & \\
\hline \multicolumn{4}{|l|}{ State } \\
\hline Shimalia & $168(7.3)$ & 338 (13.5) & \multirow{6}{*}{$<0.001$} \\
\hline Gezira & 548 (23.7) & 560 (22.3) & \\
\hline Sinnar & 584 (25.2) & 733 (29.2) & \\
\hline Nahr Al Nil & $118(5.1)$ & $420(78.1)$ & \\
\hline White Nile & 366 (15.8) & $195(7.8)$ & \\
\hline Gadarif & $533(15.8)$ & $263(10.5)$ & \\
\hline \multicolumn{4}{|l|}{ Marital status } \\
\hline Single & $873(37.9)$ & 1539 (62.5) & \multirow{4}{*}{$<0.138$} \\
\hline Married & 1377 (59.7) & 867 (35.2) & \\
\hline Divorced & $28(1.2)$ & $36(1.5)$ & \\
\hline Widowed & $28(1.2)$ & $22(0.9)$ & \\
\hline
\end{tabular}

about HIV/AIDs was explained by gender, education and religions adjusted over age of the respondents.

\section{DISCUSSION}

Sudan is a vast and wide country where the infrastructure is not yet expanded to facilitate physical accessibility among its different parts. During raining seasons, most of rural areas in Sudan are hardly accessable and some times without electricity. Communities in these areas suffer a great deal even during normal condtions to access cities or even to follow the media on a regular basis. Depending upon known means of knowledge (Newspapers, Radio and TV) to transfer knowledge to these communities has a risk of discontinuity and interruption due to electricity continuation or road accessability. All these factors play main roles in leaving these communities isolated from the access of knowledge on a regular basis. This may explain why a considerable portion of the community (52\% of the respondents) in these rural areas still don't have an adequate amount of knowledge about HIV/ AIDS with $5.1 \%$ of the respondents having not heard about HIV/AIDS, and this have increased the level of anxiety over contagion among the community. In addition, for those who have heard about HIV/AIDS, their knowledge about the mode of transmission or even protection was still poor. For example, sexual intercourse with HIV person is one of the major risks particularly among adolescents [22], but still in the study about $19.6 \%$ of the respondents ignored this main risk factor, which may aggravate the problem of HIV/AIDS in this community. As for infected blood with HIV virus or sharing the same skin injectors with HIV/AIDS case, respondents were less aware of these as risk factors, with $63.3 \%$ and $70.6 \%$ of respondents respectively aware of these risk factors.

Because these rural communities are so tied and connected and living in extended family on the same area, that made the transmission so easy and rapid if any case presenting with HIV virus is found among them [23-25]. Overall, there were misconceptions about how HIV is transmitted, such as by mosquito bites, eating or drinking with AIDS person, and sharing the same place with the affected person. This problem was addressed by many investigators such as Siemens DF and Webb PA et al. [26, 27].

The study shows that, in these communities, condoms were used as a tool for family planing and have nothing 
to do with HIV virus, and $61.8 \%$ of the respondents have not heard about condoms before. In a reserved community like that; in rural areas; the population regards talking and disscussing their sexual life as inapproporiate. It makes it difficult to measure their knowledge and seeking behavior in this regard, which leave the door locked and make they become victims of social stigma that increases their problem not only for HIV/AIDS as well as for other sexually transmitted diseases.

The media (Televison and radio) were the most common means of obtaining information about HIV/AIDS among respondents in these rural communities, but not the most credible sources. This was consistent with the study by Brook [28], i.e., "Newspapers and Magazines" were associated with the most accurate knowledge about HIV/AIDS. Studies in Southeast Asia have shown that media have done little to change existing cultural values and prejuidice about sexuality and the situation of people who are living in closed communities [29].

During the student's compiagn, people in these areas showed great interest to know more about HIV/AIDS and were ready to listen and change. All misconceptions and wrong knowledge were corrected for individuals by the students during house to house visits, public lectures and awarness raising sessions.

This study will assist SNAP policy makers and health care providers to improve tools and health education modules in order to equip the rural communitites with information about HIV/AIDS in an efficient manner. Partenership between SNAP and community leaders, teachers, Imam of mosques, etc. can be proof effective in the training of the community.

\section{REFERENCES}

[1] Nasir, E.F., Astrom, A.N., Jamil David, J. and Ali, R.W. (2008) HIV and AIDS related knowledge, source of information, and reported need for further education among dental students in Sudan across sectional study. BMC Public Health, 8-286.

[2] Zucca, M.L., Spiegel, P. and Ciantia, F. (2005) AIDS, conflict and the media in Africa: Risks in reporting bad data badly. Emerging Themes in Epidemiology, 2, 2-12. doi:10.1186/1742-7622-2-2

[3] UNAIDS (2008) 2008 report on the global aids epidemic. World Health Organization and UNAIDS, Geneva.

[4] Astrom, A. and Nasir, E. (2009) Predicting intention to treat HIV infected patients among Tanzanian and Sudanese medical and dental student using the theory of planned behaviour-A cross sectional study. BMC Health Services Research, 9, 213. doi:10.1186/1472-6963-9-213

[5] Nasir, E., Astrom, A., Ali, R. and David, J. (2009) Utlization of health care services in the context of HIV epidemic - A cross sectional of dental patients in the Sudan. BMC Oral Health, 9, 30.
[6] Spiegel, B.P. (2004) HIV /AIDS among conflict-affected and displaced population: Dispelling myths and taking action. Disasters, 28, 322-339. doi:10.1111/j.0361-3666.2004.00261.x

[7] (2007) Health Information System Assessment. Sudan Report. Draft 1.

[8] Goffman, E. (1963) Stigma: Notes on the management of spoiled identity. Prentice-Hall, Englewood Cliffs.

[9] Herek, G.M. and Glunt, E.K. (1988) An epidemic of stigma: Public reactions to AIDS. American Psychologist, 43, 886-891. doi:10.1037/0003-066X.43.11.886

[10] Herek, G.M., Capitanio. J.P. and Widaman, K.F. (2003) Stigma, social risk, and health policy: Public attitudes toward HIV surveillance policies and the social construction of illness. Health Psychology, 22, 533-540. doi:10.1037/0278-6133.22.5.533

[11] Herek, G.M. and Capitanio, J.P. (1998) AIDS stigma and HIV-related beliefs in the United States: Results from a national telephone survey. Conference Record of the 12th World AIDS. Geneva.

[12] Herek, G.M. and Glunt, E.K. (1991) AIDS related attitudes in the United States: Preliminary conceptualization. Journal of Sex Research, 28, 99-123. doi:10.1080/00224499109551597

[13] Schwartz, J. (1992) Buchanan calls AIDS “nature’s retribution.” San Francisco Examiner.

[14] Elkamel, F.M. (1996) Can mass media prevent AIDS: The need for well-planned behavior change communication programs. Eastern Mediterranean Health Journal, 2, 449458.

[15] El-Mardi, E. (2008) The price of silence: HIV/AIDS control in Sudan. Sudan Tribune, Philadelphia.

[16] Gray, L.A., Devadas, R.P., Vijayalakshmi, O. and Kamalanathan, G. (1999) Knowledge, attitudes, beliefs about HIV/AIDS among Hindu students from a government women's college of South India. International Journal for the Advancement of Counseling, 21, 207-219. doi:10.1023/A:1005419002977

[17] Irwin, K., Bertrand, J., Mibandumba, N., Mbuyi, K., Muremeri, C., Mukoka, M., Munkolenkole, K., Nzilambi, N., Bosenge, N., Ryder, R., Peterson, H., Lee, N.C., Wingo, P., Reilly, K.O. and Rufo, K. (1991) Knowledge, attitudes and beliefs about HIV infection and AIDS among healthy factory workers and their wives, Kinshasa, Zaire. Social Science \& Medicine, 32, 917-930. doi:10.1016/0277-9536(91)90247-A

[18] Dandona, R., Dandona, L., Gutierrez. J.P., Kumar, A.G., McPherson, S., Samuels, F., Bertozzi, S.M. and the ASCI FPP Study Team (2005) High risk of HIV in non-brothel based female sex workers in India. BMC Public Health, 5, 87. doi:10.1186/1471-2458-5-87

[19] (2008) United Nations General Assembly Special Session on HIV/AIDS (UNGASS). Report 2006-2007.

[20] Travis, P., Bennett, S., Haines, A., Pang, T., Bhutta, Z., Hyder, A.A., Pielemeier, N.R., Mills, A. and Evans, T. (2001) Overcoming health-systems constraints to achieve the Millennium Development Goals. The Lancet, 364, 900906. doi:10.1016/S0140-6736(04)16987-0 
[21] Kalichman, S.C. and Simbayi, L.C. (2003) HIV testing attitudes, stigma, and voluntary HIV counselling and testing in a black township in Cape Town, South Africa. Sexually Transmitted Infections, 79, 442-447.

[22] Kimbombo, R., Neema, S. and Ahmed, F.H. (2007) Perceptions of risk of HIV infection among adolescents in Uganda: Are they related to sextual behaviour. African Journal of Reported Health, 11, 168-181. doi: $10.2307 / 25549738$

[23] Tedd, V.E., Chamblee, S., Timothy, J.B., Johnson, J.W., Bryan, M.J., Lowell, P., Trenschel, R.J., Reyn, C.F., Johnson, L.S. and Horsburg C.R. (2004) Human Immunodeficiency Virus Infection in a Rural Community in the United States. American Journal of Epidemiology, 160, 582588.

[24] Bloom, S., Urassa, M., Isingo, R., Ng’Weshemi, J. and Boerma, J. (2002) Community effects on the risk of HIV in rural Tanzania. Sexually Transmitted Infections, 78, 261266. doi:10.1136/sti.78.4.261

[25] Naik, E., Karpur, A., Taylor, R., Ramaswami, B., Rama- chandra, S., balasubramaniam, B., Galwankar, J.S., Sarah, N. and Hamisu, M.S. (2005) Rural Indian tribal communities S: An emerging high-risk group of HIV/AIDS. BMC International Health and Human Rights, 5, 1. doi:10.1186/1472-698X-5-1

[26] Siemens, D.F. (1987) AIDS transmission and insects. Science, 238, 134. doi:10.1126/science.2889266

[27] Mahat, G. and Scoloveno, A.M. (2006) An HIV/AIDS Education intervention for nepalese adolescent females. Nursing Clinics of North America, 41, 409-423. doi:10.1016/j.cnur.2006.05.004

[28] Brook, U. (1999) AIDS knowledge and attitudes of pupils attending urban high school in Israel. Patient Education and Counseling, 36, 271-278. doi:10.1016/S0738-3991(98)00142-6

[29] Wolffers, I. (1997) Culture, media, and HIV/AIDS in Asia. Lancet, 349, 52-54. doi:10.1016/S0140-6736(96)07032-8 